\title{
Coincidence the Autosomal Recessive Polycystic Kidney Disease With Placenta Membranacea (A Probably Genetic Relation with PKHD1 Gene)
}

\author{
Ehsan Hosseini, ${ }^{1}$ Samira mis Ghavam,, ${ }^{2,}$ and Mohammad Reza Hafezi-Ahmadi ${ }^{3}$ \\ ${ }^{1}$ Department of Physiology, Faculty of Para-Veterinary Medicine, Ilam University, Ilam, IR Iran \\ ${ }^{2}$ Department of Cardiology, Faculty of Medical Sciences, Ilam University of Medical Sciences, Ilam, IR Iran \\ ${ }^{3}$ Department of Pathology, Faculty of Medical Sciences, Ilam University of Medical Sciences, Ilam, IR Iran \\ "Corresponding author: Samira mis Ghavam, Department of Cardiology, Faculty of Medical Sciences, Ilam University of Medical Sciences, Ilam, IR Iran. E-mail: \\ samira.gavam@yahoo.com
}

Received 2015 February 09; Accepted 2015 September 25.

\begin{abstract}
Placenta membranacea is one of the most barley anomalies happens in pregnancy defined by chorionic villi (partially or completely) covered the fetus membrane. Autosomal recessive polycystic kidney disease in fetus is also a rare case with an incidence of 1:20,000 live births resulting in a 30\% death rate in neonates. In this case for the first time, we reported a placenta membranacea and autosomal recessive polycystic kidney disease occurred with together. A 25-year-old woman was admitted at 16 weeks of gestation for inducing abortion with autosomal recessive polycystic kidney disease in fetus diagnosed in routine sonography fellowship. Postdelivery examination revealed a placenta totally enveloped the fetus, oligohydramnious and bilateral enlarged polycystic kidneys of fetus. Histological study indicated umbilicus has only one artery and one vein as well as autosomal recessive polycystic kidney disease and directly attachment of chorionic villi to fetal membrane eventually diagnosed as complete placenta membranacea. The etiology of placenta membranacea is not completely clarified. As autosomal recessive polycystic kidney disease is a result of mutation in PKHD1 gene, so our finding may be initiates a new investigation about genetic relation between placenta membranacea and autosomal recessive polycystic kidney disease.
\end{abstract}

Keywords: Abortion, Polycystic kidney disease, Placenta Disorder, Genetic Correlation

\section{Introduction}

Placenta membranacea is scarcely encountered anomaly in which fetal membranes (complete or partial) are covered by functioning villi and the placenta develops as a thin membranous structure occupying the entire periphery of the chorion and placental mass may be often thin and even disrupted [1] for the first time defined by Senesa Sargent, placenta membranacea has already been informed in 1 of $20,000-40,000$ birth $[1,2]$. On the base of latest study in 2013 only 41 cases were reported [3]. This anomaly, pathophysiologically is reasoned by defective differentiate of trophoblastic shell in to the chorion frondosum and chorion leave at 8 -10 weeks of gestation which result in membranes are covered by chorionic villi $[4,5]$. Most of cases prevalently present in the second and third trimesters with of recurrent vaginal bleeding history [2, 6]. Placenta membranacea is accompanied with, preterm delivery, fetal death, intra-uterine growth retardation, post-partum haemorrhage and placental retention [2]. Autosomal recessive polycystic kidney disease (ARPKD) is an important cause of childhood renal- and liver-related morbidity and mortality with variable disease expression. Its major clinical manifestations include ectasia of renal collecting and hepatic biliary ducts and fibrosis of both the liver and kidney $[7,8]$. The estimated incidence of ARPKD ranges from 1 in 20,000 to 1 in 40,000 live births [9]. In the present case we reported the first concurrent incidence of two very rare of fetal abnomally ARPKD and placenta membranacea in a fetus.

\section{Case Presentation}

\subsection{Patient}

A 25-year-old woman at her first gestation was admitted for inducing abortion with ARPKD in fetus diagnosed in routine sonography fellowship. The age of pregnancy was estimated 16 weeks. Abortion induced with prostaglandin and fetus was studied histologically for ARPKD. During the gross and histological examination of aborted fetus, placenta membranacea was detected in stillbirth. 


\subsection{Hematological Findings}

A decrease in hematocrit, hemoglobin, mean corpuscular volume (MCV), mean corpuscular hemoglobin $(\mathrm{MCH})$ was seen. There is not any other abnormality in hematological profile including liver and thyroid enzymes.

\subsection{Macroscopic Examination of Aborted Fetus}

The specimen received in formalin consists of fragment including a placenta totally enveloped the fetus. Inside the membranous placenta is a well preserved female fetus. Crown-rump and crown heel lengths are 120 and 220 $\mathrm{mm}$, weighs $230 \mathrm{~g}$. External feature reveals flat face due to apparently oligohydroamnious (Figure 1). Internal evaluation reveals bilateral enlarged polycystic kidneys (Figure 2). The umbilical cord measuring $28 \mathrm{~cm}$ long has two vessels. The umbilical cord indicates no unusual vascular pattern, areas of excessive helical twist, false knot and varix or amniotic adhesion. A series of sections trough the body of placenta show the cut surface to be normally spongy, moist and dark red with no apparent pathologic lesion. Trimmed body of placenta weighs $110 \mathrm{~g}$.

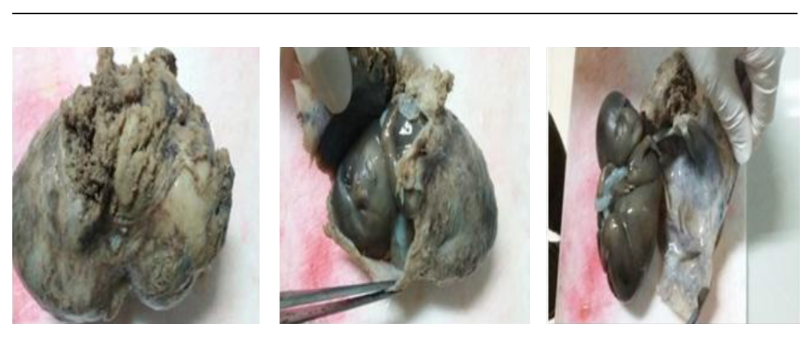

$\overline{\text { Figure 1. Fetal Membranes and Fetus With Umbilicus Completely Covered by Chori- }}$ onic Villi (Gross Appearance)

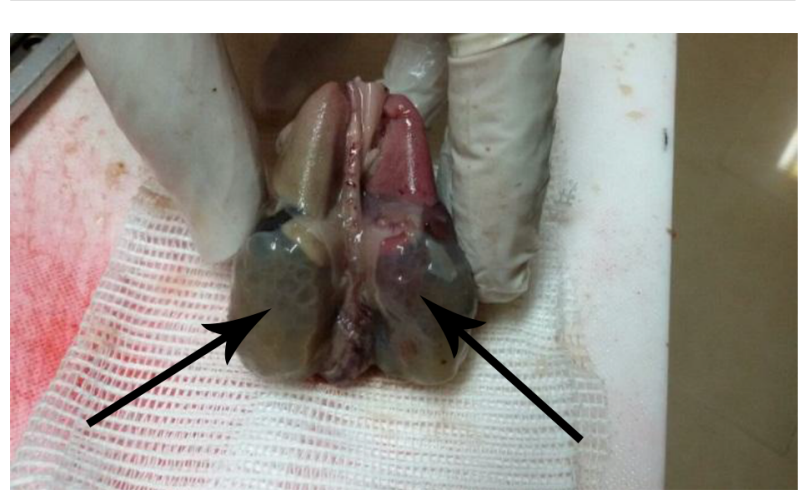

$\overline{\text { Figure 2. Coudal Appearance of Viscera of Fetus Indicating Polycystic Large Kidneys }}$

\subsection{Microscopic Diagnosis}

A well preserved female fetus with Potter phenotype to oligohydramnious (Figure 1).

-placental membranacea (Figure 3).

-Autosomal recessive (infantile) polycystic kidney disease. (Figure 4).

-Single umbilical artery (Figure 5).

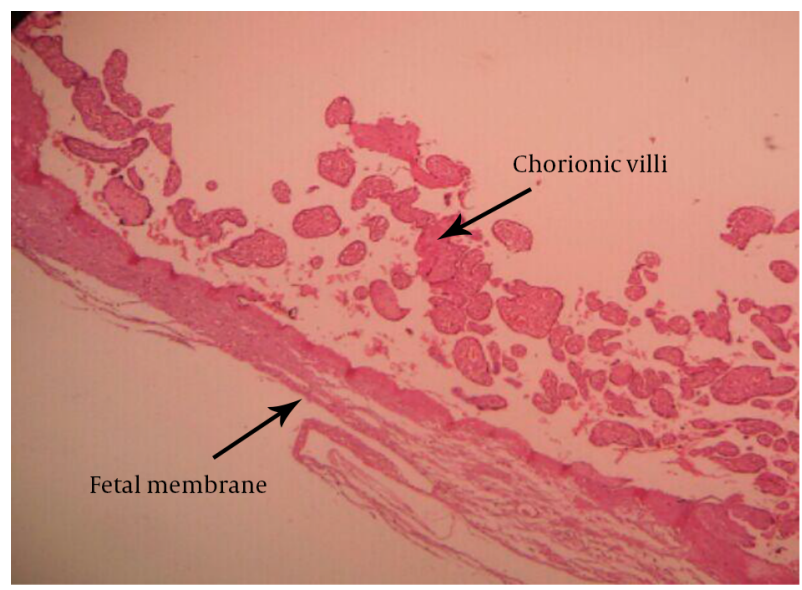

Figure 3. Histologic Appearance of Chorionic Villi Attached to Fetal Membrane Indicating Placental Membranacea

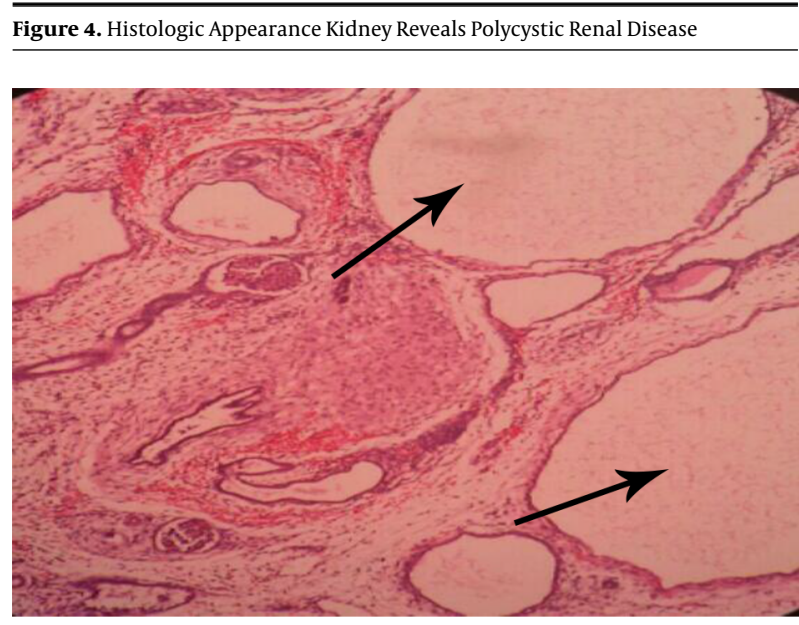

Arrows indicate cystic spaces in renal tissue.

\section{Discussion}

Placentae membranacea take place when chorionic villi are spread all over the amniotic sac as a result of failure of regression in the first trimester [10] and subsequently occurred in second or third trimester of gestation $[2,6]$. 
Figure 5. Histologic Appearance of Umbilicus Cord Demonstrating Only One Artery (Normal Umbilicus Usually has Couple of Arteries)

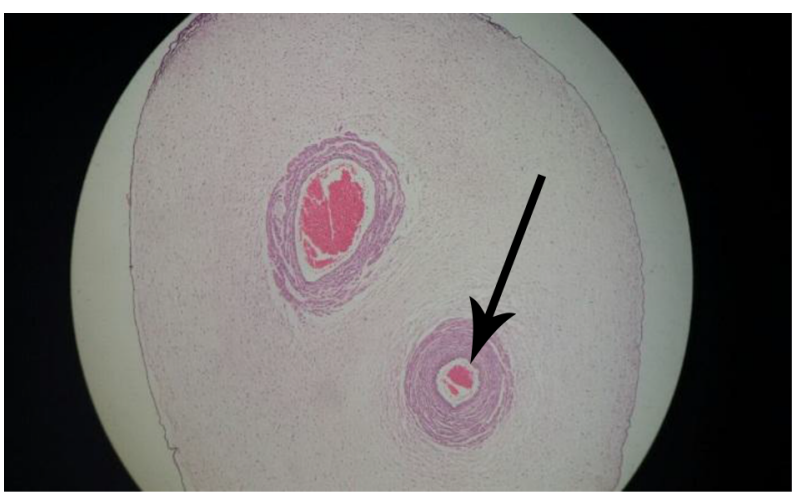

Arrows indicate only one artery in umbilicus cord.

The etiology is not entirely clarified, but it appears clear that those villi designed to degenerate and produce the chorion laeve are retained while there is lack of growth of the villi ordained to become the chorion frondosum. Underlying reasons postulated for lack of villous growth associate mostly to anomalies of the endometrium such as endometrial hypoplasia, poor vascular supply of the decidua basalis, endometritis, multiple curettages, adenomyosis or atrophy of the endometrium placenta membranacea may manifest clinically as early bleeding and placenta previa [8]. Affected gestations frequently result in premature delivery and placenta accreta is rather prevalent. Spontaneous abortion and second trimester fetal death have also been informed [8]. In this complication placenta have been characterized by tan colored membrane with outspread placental cotyledons $[3,11]$. In our case, only one artery was seen in umbilicus, an anomaly was seen with incidence of $1 \%$ and fetus kidneys were detected polycystic. We diagnosed an ARPKD in fetus characterized with an incidence of 1: 20,000 live births and is classically recognized in the first few weeks after birth resulting in a 30\% death rate in neonates [12]. In ARPKD kidneys retain their shape but are larger than the normal anatomical ranges which are precisely detected in our case. Mutations in the PKHD1 gene on chromosome $6 \mathrm{p} 12$, which is among the largest human genes cause ARPKD [13,14]. Up now there are not found any basic or genetic reason for placentae membranacea [10]. In the present case, for the first time, placentae membranacea and ARPKD occurred in one fetus. As ARPKD is a result of mutation in PKHD1 so our finding may be initiate a new investigation about genetic relation between placenta membranacea and autosomal recessive polycystic kidney disease.

\section{Acknowledgments}

We appreciated Gaem medical laboratory of Ilam city (Iran) for diagnostic helps.

\section{Footnotes}

Authors' Contribution: Ehsan Hosseini and Samira mis Ghavam diagnosed the case, Mohammad Reza HafeziAhmadi contributed in gross and histological finding, Ehsan Hosseini drafted manuscript and Samira mis Ghavam edited manuscript.

Conflict of Interest: The authors declare that they have no competing interests.

Funding/Support: Ilam University of Medical Sciences.

\section{References}

1. Ekoukou D, Ng Wing Tin L, Nere MB, Bourdet O, Elalaoui Y, Bazin C. [Placenta membranacea. Review of the literature, a case report]. J Gynecol Obstet Biol Reprod (Paris). 1995;24(2):189-93. [PubMed: 7782592].

2. Greenberg JA, Sorem KA, Shifren JL, Riley LE. Placenta membranacea with placenta increta: a case report and literature review. Obstet Gynecol. 1991;78(3 Pt 2):512-4. [PubMed: 1870811].

3. Ravangard SF, Henderson K, Fuller K. Placenta membranacea. Arch Gynecol Obstet. 2013;288(3):709-12. doi: 10.1007/s00404-013-2778-z. [PubMed: 23467796].

4. Ahmed A, Gilbert-Barness E. Placenta membranacea: a developmental anomaly with diverse clinical presentation. Pediatr Dev Pathol. 2003;6(2):201-2. doi:10.1007/s10024-002-0007-z. [PubMed: 12532260].

5. Hurley VA, Beischer NA. Placenta membranacea. Case reports. Br J Obstet Gynaecol. 1987;94(8):798-802. [PubMed: 3311135].

6. Heras JL, Harding PG, Haust MD. Recurrent bleeding associated with placenta membranacea partialis: report of a case. Am J Obstet Gynecol. 1982;144(4):480-2. [PubMed: 7124871].

7. Potter EL. Normal and abnormal development of the kidney. Year Book Medical Publishers; 1972.

8. Bosniak MA, Ambos MA. Polycystic kidney disease. Semin Roentgenol. 1975;10(2):133-43. [PubMed: 1096305].

9. Zerres K, Rudnik-Schoneborn S, Senderek J, Eggermann T, Bergmann C. Autosomal recessive polycystic kidney disease (ARPKD). J Nephrol. 2003;16(3):453-8. [PubMed: 12832752].

10. Bartholomew ML, Zalud I, Holzman J, Kurjak A, Chervenak FA. Ultrasound of the Placenta. Donald School Journal of Ultrasound in Obstetrics \& Gynecology. 2007:47-60. doi:10.5005/jp-journals-10009-1119.

11. Baergen RN. Manual of Benirschke and Kaufmann's pathology of the human placenta. Springer Science \& Business Media; 2005.

12. Bisceglia M, Galliani CA, Senger C, Stallone C, Sessa A. Renal cystic diseases: a review. Adv Anat Pathol. 2006;13(1):26-56. doi: 10.1097/01.pap.0000201831.77472.d3. [PubMed: 16462154].

13. Bergmann C, Kupper F, Dornia C, Schneider F, Senderek J, Zerres K. Algorithm for efficient PKHD1 mutation screening in autosomal recessive polycystic kidney disease (ARPKD). Hum Mutat. 2005;25(3):225-31. doi: 10.1002/humu.20145. [PubMed: 15706593].

14. Zhang MZ, Mai W, Li C, Cho SY, Hao C, Moeckel G, et al. PKHD1 protein encoded by the gene for autosomal recessive polycystic kidney disease associates with basal bodies and primary cilia in renal epithelial cells. Proc Natl Acad Sci U S A. 2004;101(8):2311-6. [PubMed: 14983006]. 